\title{
A Multicenter Study of Viral Aetiology of Community-Acquired Pneumonia in Hospitalized Children in Chinese Mainland
}

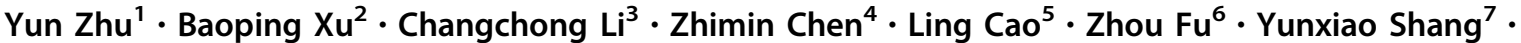 \\ Aihuan $\mathrm{Chen}^{8} \cdot \mathrm{Li}^{\mathrm{Deng}}{ }^{9} \cdot$ Yixiao Bao ${ }^{10} \cdot$ Yun Sun ${ }^{11} \cdot$ Limin Ning $^{12} \cdot$ Shuilian $\mathrm{Yu}^{13} \cdot$ Fang Gu $^{14}$. \\ Chunyan Liu ${ }^{1} \cdot J_{\text {Yin }}{ }^{2} \cdot$ Adong Shen $^{15} \cdot$ Zhengde Xie $^{1}$ (1) Kunling Shen $^{16}$
}

Received: 10 February 2021 / Accepted: 18 June 2021 / Published online: 15 September 2021

(c) Wuhan Institute of Virology, CAS 2021

\begin{abstract}
Community-acquired pneumonia (CAP) is one of the leading causes of morbidity and mortality in children worldwide. In this study, we aimed to describe the aetiology of viral infection of pediatric CAP in Chinese mainland. During November 2014 to June 2016, the prospective study was conducted in 13 hospitals. The hospitalized children under 18 years old who met the criteria for CAP were enrolled. The throat swabs or nasopharyngeal aspirates (NPAs) were collected which were then screened 18 respiratory viruses using multiplex PCR assay. Viral pathogens were present in 56.6\% (1539/2721) of the enrolled cases, with the detection rate of single virus in $39.8 \%$ of the cases and multiple viruses in $16.8 \%$ of the cases. The most frequently detected virus was respiratory syncytial virus (RSV) $(15.2 \%, 414 / 2721)$. The highest detection rate of virus was in <6-month-age group $(70.7 \%, 292 / 413)$. RSV, human metapneumovirus (HMPV), human parainfluenza viruses (HPIVs) and influenza B virus (Flu B) showed the similar prevalence patterns both in north and south China, but HPIVs, Flu A, human bocavirus (HBoV), human adenovirus (HAdV) and human coronaviruses (HCoVs) showed the distinct circulating patterns in north and south China. Human enterovirus/human rhinovirus (HEV/HRV) (27.6\%, 27/98), HBoV (18.4\%, 18/98), RSV $(16.3 \%, 16 / 98)$ and HMPV $(14.3 \%, 14 / 98)$ were the most commonly detected viruses in severe pneumonia cases with single virus infection. In conclusion, viral pathogens are frequently detected in pediatric CAP cases and may therefore play a vital role in the aetiology of CAP. RSV was the most important virus in hospitalized children with CAP in Chinese mainland.
\end{abstract}

Keywords Children · Community-acquired pneumonia $\cdot$ Multicenter study $\cdot$ Viral aetiology $\cdot$ Multiplex PCR assay

Supplementary Information The online version contains supplementary material available at https://doi.org/10.1007/s12250021-00437-0.

Yun Zhu, Baoping Xu, Changchong Li, and Zhimin Chen contributed equally to this work.

Kunling Shen

kunlingshen1717@163.com

$\triangle$ Zhengde Xie

xiezhengde@bch.com.cn

1 Laboratory of Infection and Virology, Beijing Pediatric Research Institute, Beijing Key Laboratory of Pediatric Respiratory Infection Diseases, Research Unit of Critical Infection in Children, Chinese Academy of Medical Sciences, 2019RU016, Beijing Children's Hospital, Capital Medical University, Key Laboratory of Major Diseases in Children, Ministry of Education, National Clinical Research Center for Respiratory Diseases, National Center for Children's Health, Beijing 100045, China
2 Department of Respiratory Diseases I, Beijing Children's Hospital, Capital Medical University, National Clinical Research Center for Respiratory Diseases, National Center for Children's Health, Beijing 100045, China

3 The 2nd Affiliated Hospital and Yuying Children's Hospital of Wenzhou Medical University, Wenzhou 325027, China

4 The Children's Hospital of Zhejiang University School of Medicine, Hangzhou 310005, China

5 Children's Hospital Capital Institute of Pediatrics, Beijing 100020, China

6 Children's Hospital of Chongqing Medical University, Chongqing 400015, China

7 Shengjing Hospital of China Medical University, Shenyang 110004, China

8 The First Affiliated Hospital of Guangzhou Medical University, Guangzhou 510120, China 


\section{Introduction}

Community-acquired pneumonia (CAP) is one of the leading causes of morbidity and mortality in the children younger than five years old, especially in developing countries (DeAntonio et al. 2016; Ning et al. 2017). There are approximately 150 million children with CAP each year, with the huge financial burdens to society and family (Zhang et al. 2013; Jain et al. 2015). Early and accurate diagnosis of the aetiological cause would be helpful for effective treatment and management of children with CAP and significantly reducing mortality (Caglayan Serin et al. 2014; Chen et al. 2015). Respiratory viruses are recognized as the leading cause of children with CAP and can be detected in more than $50 \%$ of the cases (Padilla Ygreda et al. 2010; Ning et al. 2017; Oumei et al. 2018). Several studies have suggested that the role of respiratory viruses in children with CAP has been underestimated, due to the application of low sensitive detection methods (Wang et al. 2016; Chen et al. 2017; Xu et al. 2017). With the development of molecular diagnostic technologies, the novel detection assays have been increasingly applied in the diagnosis of infectious disease (Cantais et al. 2014; Mathew et al. 2015). However, the multicenter study on the profile of viral pathogens in children with CAP is scarce in Chinese mainland.

Here, we performed a multicenter study to investigate the feature of viral aetiology of hospitalized children with CAP by using multiplex PCR assay in China, and to analyze the relationship between respiratory viruses and clinical severity.

9 Guangzhou Women and Children's Medical Center, Guangzhou 510623, China

10 Xinhua Hospital Affiliated to Shanghai Jiao Tong University School of Medicine, Shanghai 200092, China

11 Yinchuan Women and Children Healthcare Hospital, Yinchuan 750000, China

12 Children's Hospital of Changchun, Changchun 130000, China

13 The 2nd Affiliated Hospital of Harbin Medical University, Harbin 150086, China

14 Baoding Children's Hospital, Baoding 071051, China

15 Laboratory of Respiratory Diseases, Beijing Key Laboratory of Pediatric Respiratory Infection Diseases, Beijing Pediatric Research Institute, Beijing Children's Hospital, Capital Medical University, Key Laboratory of Major Diseases in Children, Ministry of Education, National Clinical Research Center for Respiratory Diseases, National Center for Children's Health, Beijing 100045, China

16 Beijing Children's Hospital, Capital Medical University, National Clinical Research Center for Respiratory Diseases, National Center for Children's Health, Beijing 100045, China

\section{Materials and Methods}

\section{Study Design and Enrollment of Patients}

From November 2014 to June 2016, a prospective study was conducted in 13 children hospitals or comprehensive hospitals in north China (7 hospitals, including Beijing Children's Hospital, Capital Medical University in Beijing, Shengjing Hospital of China Medical University in Liaoning Province, Children's Hospital Capital Institute of Pediatrics in Beijing, Children's Hospital of Changchun in Jilin Province, Yinchuan Women and Children Healthcare Hospital in Ningxia Hui Autonomous Region, Baoding Children's Hospital in Hebei Province and The $2^{\text {nd }}$ Affiliated Hospital of Harbin Medical University in Heilongjiang Province) and south China (7 hospitals, including the Children's Hospital of Zhejiang University School of Medicine in Zhejiang Province, Xinhua Hospital Affiliated to Shanghai Jiao Tong University School of Medicine in Shanghai, The $2^{\text {nd }}$ Affiliated Hospital and Yuying Children's Hospital of Wenzhou Medical University in Zhejiang Province, Guangzhou Women and Children's Medical Center in Guangdong Province, The First Affiliated Hospital of Guangzhou Medical University in Guangdong Province, Children Hospital of Chongqing Medical University in Chongqing).

The diagnostic criteria of CAP as follows: patients can be diagnosed as CAP by meeting any of the following (1)(4) and (5) term with the exception of tuberculosis, noninfectious interstitial pulmonary diseases, pulmonary edema and other diseases. (1) The symptoms of cough, expectoration or preexisting respiratory diseases are increased, and purulent sputum is accompanied with or without chest pain; (2) fever; (3) signs of pulmonary consolidation and/or audible and moist rales; (4) white blood cell $(\mathrm{WBC})>10 \times 10^{9} / \mathrm{L}$ or $<4 \times 10^{9} / \mathrm{L}$, with or without nucleus left; (5) chest X-ray showed patchy, invasive, or interstitial changes with or without pleural effusion (Subspecialty Group of Respiratory Diseases, The Society of Pediatrics, Chinese Medical Association et al. 2013).

All the hospitalized children diagnosed with CAP would be screened. Children were included if their disease course were less than seven days. Cases were excluded if they were diagnosed as pneumonia after $48 \mathrm{~h}$ of admission.

The severe CAP case was defined by several factors, including cough or difficulty breathing plus one of the following: lower chest indrawing, nasal flaring, or grunting. Very severe pneumonia case was defined as cough or difficulty breathing plus one of the following: cyanosis, severe respiratory distress, inability to drink or vomiting everything, or lethargy/unconsciousness/convulsions 
(Subspecialty Group of Respiratory Diseases, The Society of Pediatrics, Chinese Medical Association et al. 2013).

\section{Specimen and Clinical Data Collection}

Respiratory specimens, including throat swabs or nasopharyngeal aspirates (NPAs), were collected by trained nurses in the first $24 \mathrm{~h}$ of hospitalization and transported to lab in viral transport media (VTM). All specimens were stored at $-80{ }^{\circ} \mathrm{C}$ until use. The demographic, epidemiologic and clinical data were recorded using a uniform case report form (CRF) by clinical researchers. All the information of CRFs was uploaded to the clinical research information platform.

\section{Molecular Detection of Viral Pathogens}

Total nucleic acids (DNA and RNA) were extracted from $200 \mu \mathrm{L}$ throat swabs or NPAs specimens using QIAamp MinElute Virus Spin Kit (Qiagen, Hilden, Germany) according to the manufacturer's instructions and eluted in $60 \mu \mathrm{L}$ elution buffers. The presence of 18 respiratory viruses, including respiratory syncytial virus (RSV A or RSV B), parainfluenza virus (PIV) type 1-4, 2009 H1N1 influenza virus (2009 H1N1), H3 subtype influenza virus (H3), seasonal H1 subtype influenza virus (H1), influenza B virus (Flu B), human rhinovirus/enterovirus (HEV/ HRV), human coronavirus (HCoV 229E, NL63, HKU1, and OC43), human metapneumovirus (HMPV), human bocavirus $(\mathrm{HBoV})$, and human adenovirus (HAdV), were simultaneously screened using Xtag RVP Fast V2 kit (Luminex, USA) with Luminex MAGPIX system. An internal positive control (MS2) was added into each specimen before the nucleic acid extraction, and a positive PCR control (Lambda DNA) was added in every PCR batch run, following the manufacturer's manual. VTM only served as a negative control for nucleic acid extraction. HEV/HRVpositive samples were further performed real-time RT-PCR for further typing HEV and HRV by using universal nucleic acid detection kit for human enterovirus (BioGerm, Shanghai, China) and universal nucleic acid detection kit for human rhinovirus (Bio-Germ).

\section{Statistical Analysis}

Continuous variables were summarized as means \pm standard deviations (SD) or median. Categorical variables are displayed as frequencies and percentages using the chisquare test or the Fisher's exact test. The continuous variables were compared using a one-way analysis of variance (ANOVA). A $P$ value $<0.05$ was considered statistically significant. All analyses were performed using SPSS software, version 19.0 (IBM Corporation, USA).

\section{Results}

\section{The Demographic and Clinical Features of Patients}

A total of 3480 children who diagonsed with CAP from 13 hospitals in Chinese mainland during November 2014 to June 2016 were screened in this study. Of 3480 children, $2721(78.2 \%)$ patients were recruited finally, and the other patients $(21.8 \%)$ were exculded because of rejection of guardians $(82.2 \%)$ or no respiratory specimen $(17.4 \%)$ (Fig. 1). The demographic and clinical characteristics of recruited cases were list in Table 1.

\section{Viral Pathogen Detection}

Viral pathogens were detected in $56.6 \%(1539 / 2721)$ of the cases, with $39.8 \%$ (1082/2721) single virus infection and $16.8 \%$ (457/2721) multiple virus infection. HEV/HRV $(73.1 \%, 334 / 457)$ was the most common virus associated with co-infection, followed by RSV (47.9\%, 219/457), HMPV $(30.0 \%, 137 / 457)$, HPIVs $(26.5 \%, 121 / 457), \mathrm{HBoV}$ (20.8\%, 95/457) and HAdV (14.2\%, 65/457). In north China, viral pathogen was detected in 54.6\% (616/1128) of the cases: single virus infection in 35.5\% (401/1128) of the cases and multiple virus infection in $19.1 \%(215 / 1128)$ of the cases. In south China, viral pathogen was detected in $57.9 \%$ (923/1593) of the cases: single virus in $42.7 \%$ (681/ 1593 ) of the cases and multiple viruses in $15.2 \%$ of the case (242/1593) (Fig. 2). There was no statistic difference in detection rate of recruited children between north China and south China $\left(\chi^{2}=2.98, P=0.0843\right)$.

The most frequently detected viral pathogen was RSV (15.2\%, 413/2721), followed by HEV (13.4\%), HRV (10.2\%) [The HEV/HRV was detected in $23.6 \%$ (643/ 2721) of the cases by using Luminex RVP Fast V2 kit. To further classify the HEV or HRV infection, real-time RTPCR (Taqman probe) assay were performed in 180 available HEV/HRV-positive samples. The HEV- and HRVpositive samples accounted for $56.7 \%(102 / 180)$ and $43.3 \%$ (78/180), respectively. According to the proportion, the detection rate of HEV and HRV should be $13.4 \%$ and $10.2 \%$, respectively], HPIVs $(9.0 \%, 244 / 2721)$, HBoV (8.7\%, 238/2721), HMPV (7.8\%, 213/2721), HAdV (5.7\%, $154 / 2721)$, Flu A $(2.5 \%, 75 / 2721)$, HCoVs $(2.6 \%$, $71 / 2721)$, Flu B $(2.5 \%, 69 / 2721)$ (Fig. 3). For HPIVs, the detection rate of HPIV1-4 was $1.6 \%$ (44/2721), 1.4\% (37/ 2721), 5.2\% (141/2721), 1.1\% (31/2721), respectively. For $\mathrm{HCoVs}$, the most common detected virus was HCoV-OC43 $(1.3 \%, 36 / 2721)$, and the positive rate of other three HCoVs, 229E, NL63, HKU1, was $0.6 \%$ (15/2721), 0.1\% (4/2721), $0.7 \%$ (18/2721), respectively. In 75 Flu 


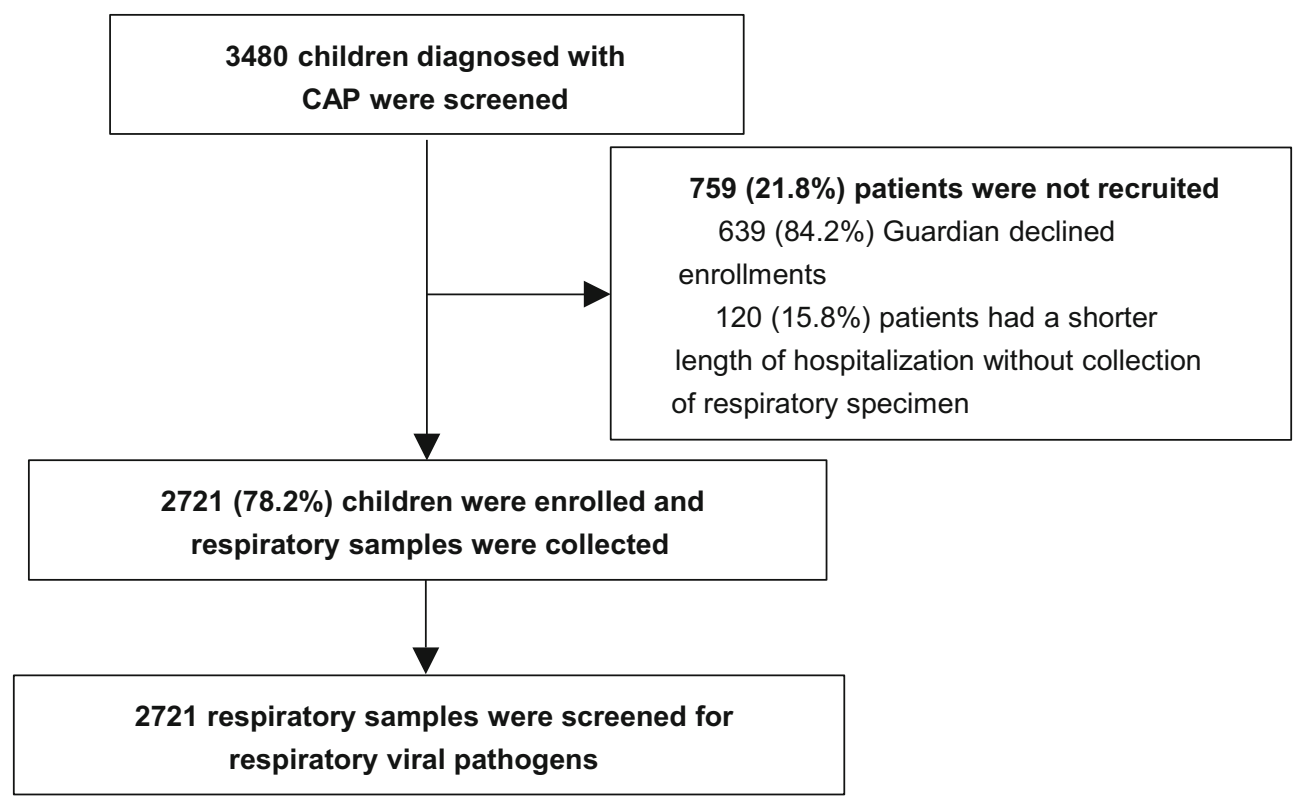

Fig. 1 Recruitment of children diagnosed with CAP. CAP: community-acquired pneumonia.

Table 1 Demographic and clinical data of children with CAP

\begin{tabular}{ll}
\hline Characteristics & $\mathrm{n}(\%)$ \\
\hline Gender & \\
Male & $1698(60.7)$ \\
Female & $1092(39.3)$ \\
Age & \\
Median & $2.17 \mathrm{y}$ \\
Age group & \\
$<6$ m & $413(15.2)$ \\
6-12 m & $362(13.3)$ \\
1-3 y & $824(30.2)$ \\
3-5 y & $511(18.8)$ \\
5-18 y & $611(22.5)$ \\
Symptom & \\
Fever & $2043(75.1)$ \\
Cough & $2664(97.9)$ \\
Expectoration & $1012(37.2)$ \\
Wheeze & $985(36.2)$ \\
Hemoptysis & $16(0.6)$ \\
The major complications of severe pneumonia case & $240(8.8)$ \\
Acute respiratory failure & $77(32.1)$ \\
Pleural effusion & $42(17.5)$ \\
Atelectasis & $26(10.8)$ \\
Cardiac damage & $9(3.8)$ \\
\hline CAP commnty- &
\end{tabular}

CAP: community-acquired pneumonia

A-positive samples, the 2009 pandemic H1N1 influenza A virus accounted for $20 \%$ (15/75), H3 subtype influenza A virus accounted for $22.7 \%$ (17/75), while the rest part was unsubtyped Flu A $(57.3 \%, 43 / 75)$. The detection rate of
HPIVs, HBoV and Flu B in north China were significantly higher than that in south China (HPIVs: $\chi^{2}=8.735$, $P=0.0031$, HBoV: $\chi^{2}=14.99, P=0.0001$ and Flu B: $\left.\chi^{2}=25.28, P<0.0001\right)$. However, the detection rate of RSV and HMPV in north China were significantly lower than that in south China (RSV: $\chi^{2}=11.67, P=0.0006$ and HMPV: $\chi^{2}=8.735, P=0.0031$ ). There were no statistic differences in detection rate of HEV/HRV, HAdV, Flu A and $\mathrm{HCoVs}$ between cases in north and south China.

Severe pneumonia patients accounted for $8.8 \%$ (240/ 2721) in children with CAP. The major complications included acute respiratory failure $(32.1 \%, 77 / 240)$, pleural effusion $(17.5 \%, 42 / 240)$, atelectasis $(10.8 \%, 26 / 240)$, cardiac damage $(3.8 \%, 9 / 240)$ (Table 1). Of all severe pneumonia cases, $40.8 \%(98 / 240)$ patients were infected with single virus, while $19.2 \%$ (46/240) patients were coinfected with multiple viruses. However, 40.0\% (96/240) severe pneumonia cases were viral pathogen-negative. HEV/HRV (27.6\%, 27/98), HBoV (18.4\%, 18/98), RSV $(16.3 \%, 16 / 98)$ and HMPV $(14.3 \%, 14 / 98)$ were the most common detected viral pathogens in patients with single virus infection (Fig. 4).

\section{Comparison of Detection Rate of Viral Pathogens in Different Age Groups}

The detection rates of viral pathogen decreased gradually with the increase of age. The detection rate of virus was the highest in children younger than six months old $(70.7 \%$, 292/413). There were significantly difference among five age groups $\left(\chi^{2}=207.89, P<0.001\right)$ (Fig. 5). RSV and $\mathrm{HRV} / \mathrm{HEV}$ were the most frequently detected viruses 


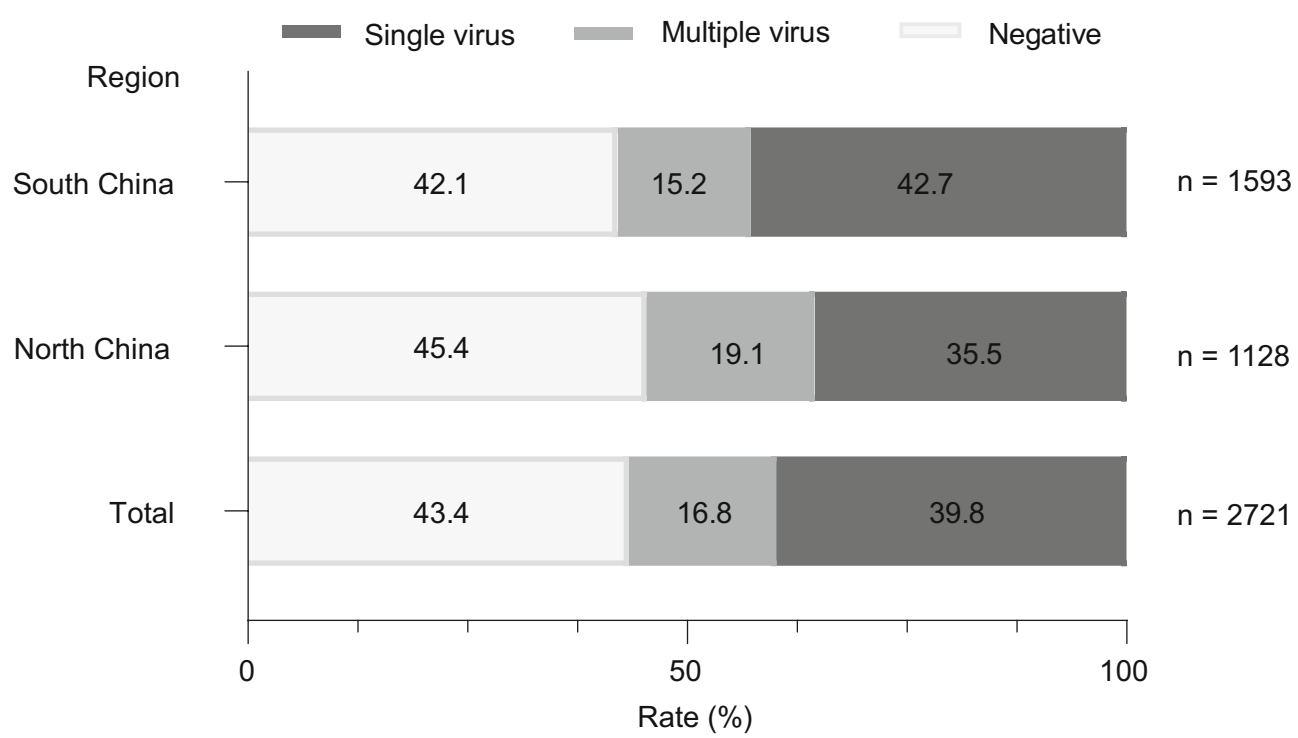

Fig. 2 Detection rate of viral pathogens in children with CAP. CAP: community-acquired pneumonia.

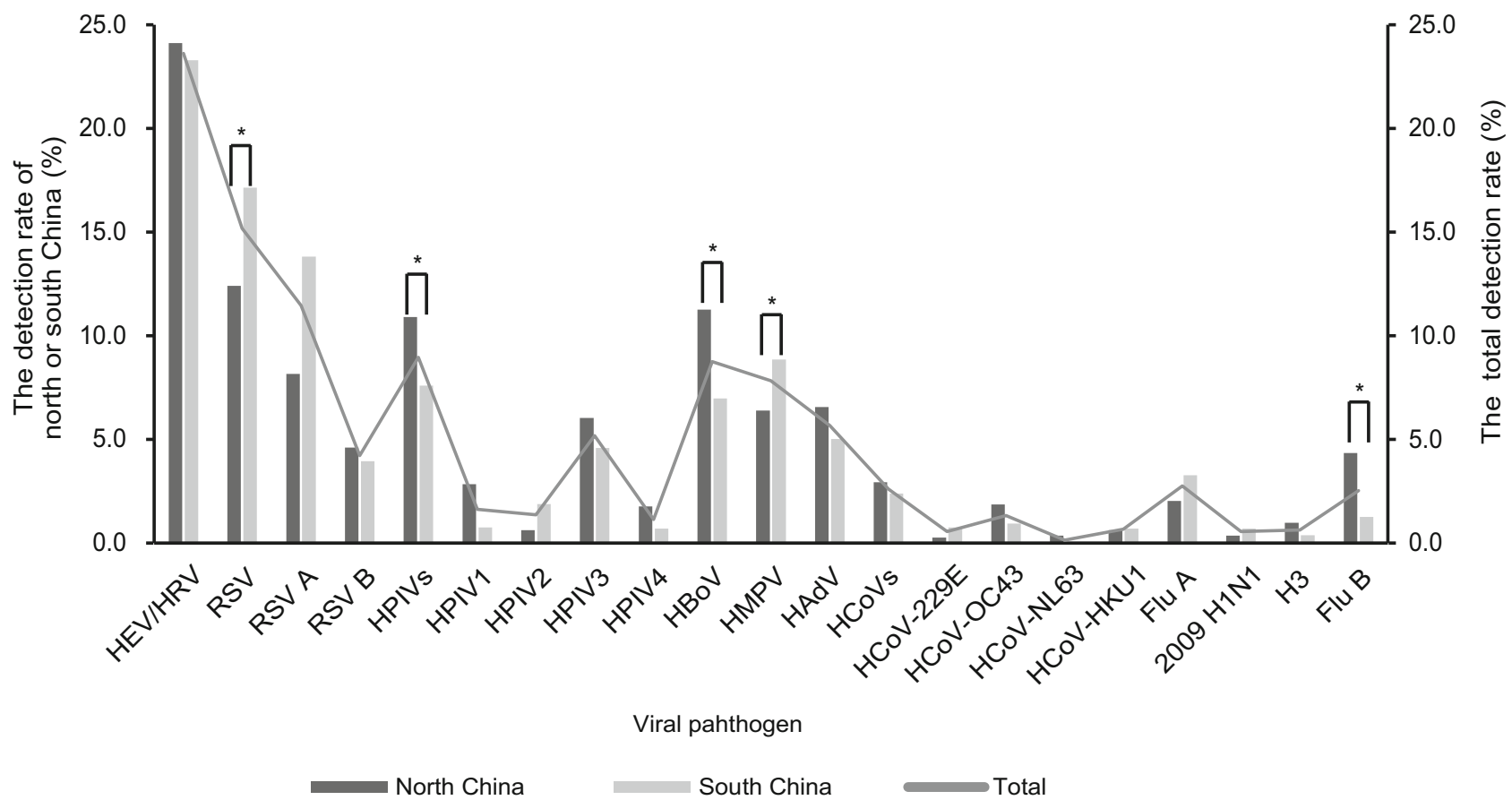

Fig. 3 Detection rate of different viruses or virus subtypes in children with CAP. CAP: community-acquired pneumonia; RSV: respiratory syncytial virus; HEV/HRV: human enterovirus/human rhinovirus; HPIVs: human parainfluenza viruses (including HPIV1-4); HBoV: human bocavirus; HMPV: human metapneumovirus; HAdV: human adenovirus; Flu A: influenza A virus (including 2009 pandemic H1N1

in $<6$ months, $6-12$ months and $1-3$ years groups. HBoV, HPIVs and HAdV were more commonly detected in children aged between 1-3 years. HMPV showed more often in children younger than five years. And similar detection rates were found among $<6$ months, 6-12 months, $1-3$ years and 3-5 years age groups. Flu A and Flu B influenza A virus, H3 subtype influenza A virus); HCoVs: human coronavirus (including HCoV-229E, -OC43, -NL63 and -HKU1); Flu B: influenza B virus. The symbol "*” indicated that there was statistic difference in the detection rate between north and south China using the chi-square test or the Fisher's exact test. A $P<0.05$ was considered statistically significant.

showed the highest detection rate in cases between 1-3 years old and 3-5 years old, respectively. HCoVs were the most common pathogens appeared in $<6$ months group (Supplementary Table 1). 


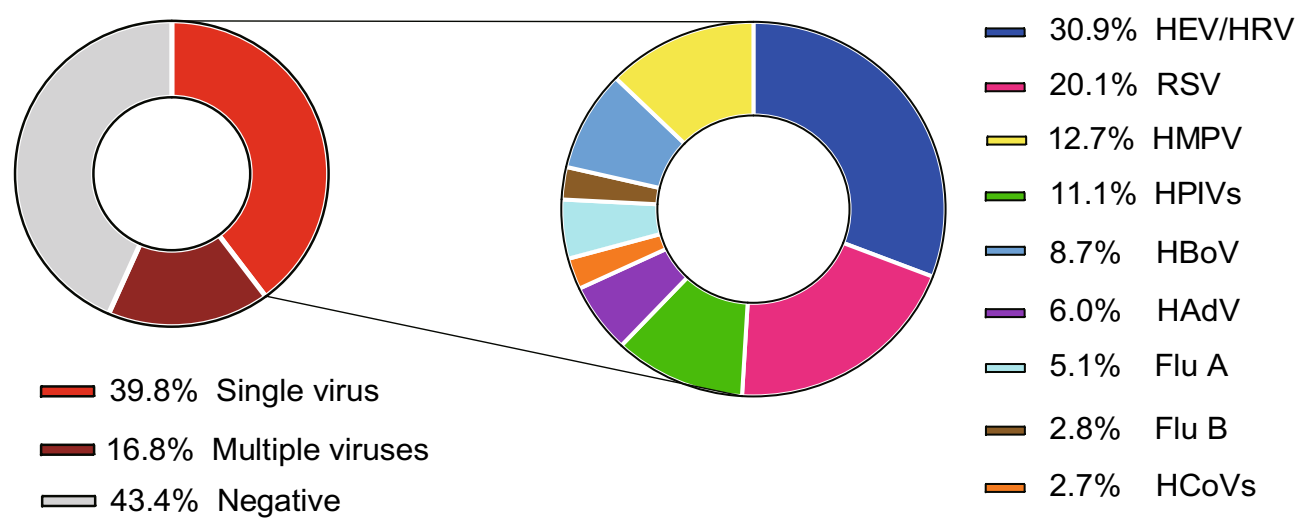

Fig. 4 Spectrum of viral pathogens in severe CAP cases. CAP: community-acquired pneumonia; RSV: respiratory syncytial virus; HEV/HRV: human enterovirus/human rhinovirus; HPIVs: human parainfluenza viruses (including HPIV1-4); HBoV: human bocavirus;

\section{Seasonal Characteristic of Viral Pathogens in North and South China}

RSV, HMPV and Flu B infection peaked in winter both in north and south China. Infection of Flu A reached the peak in winter and spring in north China, while peaked in summer in south China. HPIV infection was most frequently detected in summer both in north and south China. HEV/HRV infection circulated all year round, which showed higher detection rate from spring to summer. $\mathrm{HBoV}$ were more prevalent in summer in north China, but the peak of $\mathrm{HBoV}$ infection occurred in winter and summer in south China. Though HAdV was detected more often during winter than other seasons in north China, it kept lower prevalence in south China. The detection rate of HCoVs ascended in spring and summer in north China, which showed lower level in south China all year round (Fig. 6A, 6B).
HMPV: human metapneumovirus, HAdV: human adenovirus; Flu A: influenza A virus (including 2009 pandemic H1N1 influenza A virus, $\mathrm{H} 3$ subtype influenza A virus); HCoVs: human coronavirus (including HCoV-229E, -OC43, -NL63 and -HKU1); Flu B: influenza B virus.

\section{Discussion}

Here we performed a prospective, multicenter study of viral aetiology of CAP in hospitalized children at 13 sites nationwide from 2014 to June 2016. In this study, we used the multiplex assay to simultaneously detect 18 respiratory viruses in respiratory specimens from children with CAP. The assay exerted higher sensitivity and specificity, and provided clinicians with more accurate diagnosis and treatment information (Choudhary et al. 2016). In this study, the overall detection rate of viral pathogen was $56.6 \%$, which was similar in north $(54.6 \%)$ and south China $(57.9 \%)$. The previous studies reported that respiratory virus infection was present in 30\%-73\% of hospitalized children with CAP (Ning et al. 2017; Oumei et al. 2018). The various results between our study and previous reports might be attributed to the difference of study

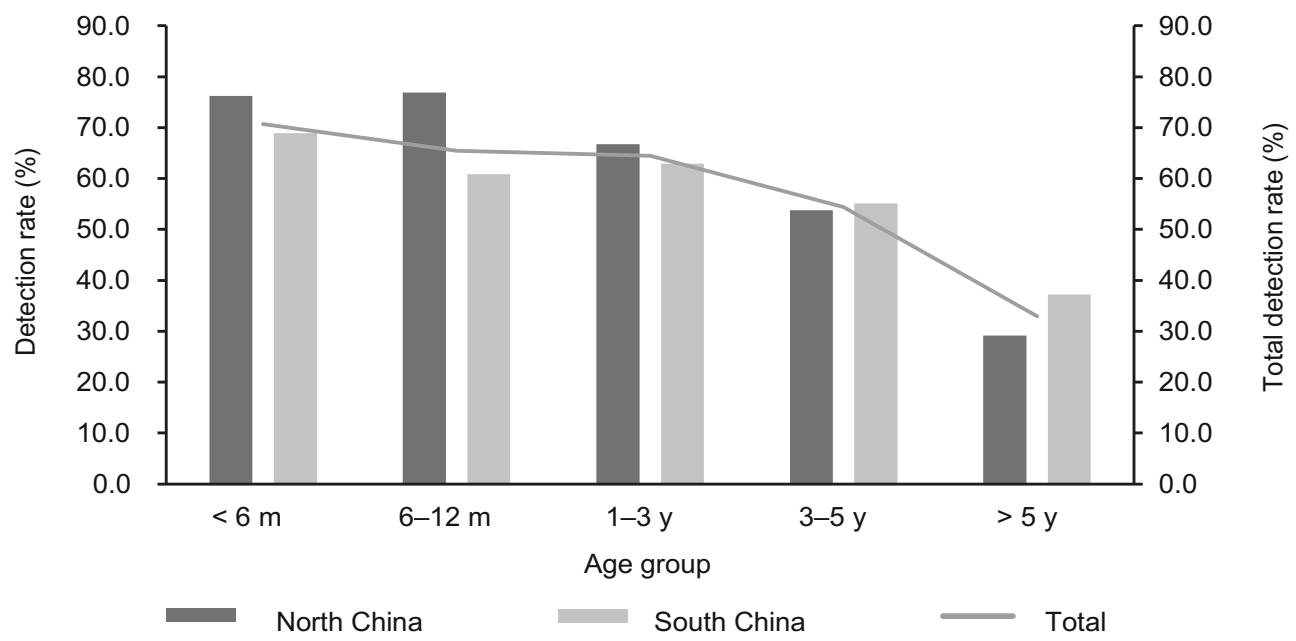

Fig. 5 Comparison of detection rate of viral pathogens in different age groups between north and south China. 

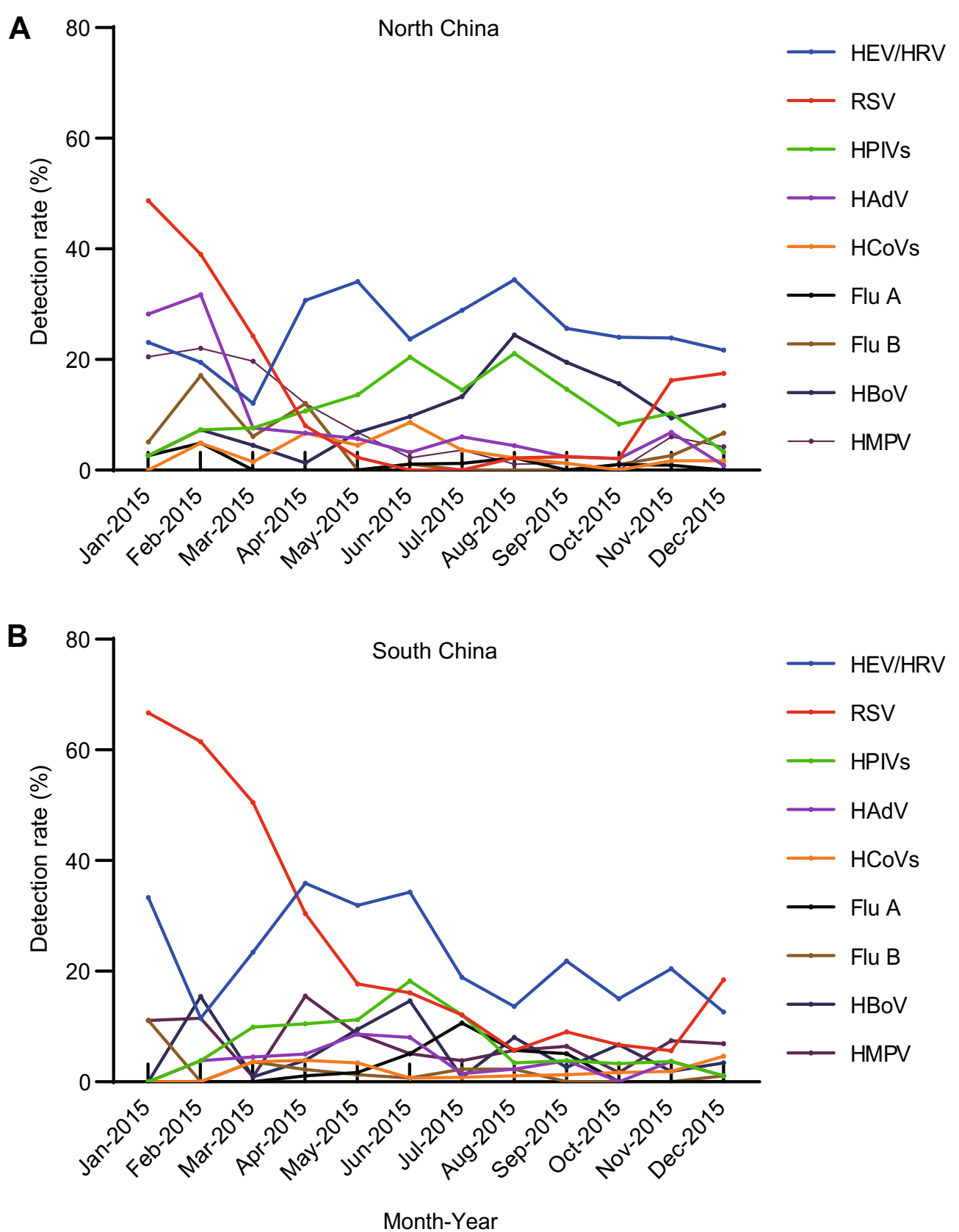

Fig. 6 Monthly detection rate of viral pathogens in hospitalized CAP children in north and south China in 2015. A Monthly detection rate of viral pathogens in north China in 2015. B Monthly detection rate of viral pathogens in south China in 2015. CAP: community-acquired pneumonia.

population, study region, the year of analysis or detection method.

In Chinese mainland, the incidence of pneumonia in children younger than 5 years of age ranged from 0.06-0.27 episodes per person-year and mortality varied between 184 and 1223 deaths per 10,000 population, which caused huge social and economic burdens (Guan et al. 2010). In present study, children under 5 years old with CAP accounted for $77.5 \%$ (2110/2721) of cases. The most commonly detected viral pathogens were RSV (18.9\%), followed by HEV (13.9\%), HRV (11.7\%), HPIVs (10.4\%), HBoV (10.1\%), HMPV (9.1\%), HAdV (5.9\%), Flu (5.1\%, Flu A 2.7\%; Flu B 2.4\%) and HCoVs (3.0\%) (The detection rate of HEV and HRV were estimated based on the results of real-time RT-PCR of 162 available specimens from children under 5 years old). A systematic review indicated that RSV (17.3\%), aside from HRV (20.3\%, detected in only two studies), was the most common detected viruses, followed by $\mathrm{HBoV}(9.9 \%)$, HPIVs (5.8\%), HMPV (3.9\%), and Flu (3.5\%) in children under 
5 years old with CAP in Chinese mainland (Ning et al. 2017). Because HRV was detected only in two studies with small sample size, the detection rate of HRV in this review might be a statistical bias. Another study reported that the most frequently identified viruses were RSV (28\%), HRV (27\%), HMPV (13\%), HAdV and Flu (7\%) and HCoVs (5\%) among U.S. hospitalized children with CAP (Jain et al. 2015). Together, these studies suggested that RSV was the most frequently detected viral pathogen in children with CAP.

RSV is the most important viral agent of CAP in children, which is also the most frequently detected viral pathogen in children with CAP under 5 years old. The detection rate of RSV infection declined gradually with increasing of age (Berkley et al. 2010; Nair et al. 2010). In this study, the detection rate of RSV in patients less than 5 years old was the highest (18.9\%). Another multicenter study using direct immunofluorescence assays (DFA), reported that RSV was the most predominant viral pathogen $(11.5 \%)$ in 1500 hospitalized children with CAP in Chinese mainland (Oumei et al. 2018), which was similar to our result, but lower than ours, due to the poor sensitivity of DFA assay.

HEV and HRV were members of the Picornaviridae family, which was underestimated its important role in CAP before (Garcia et al. 2013; Ren et al. 2017). HRV infections in young children were usually subclinical or accompanied by other respiratory pathogens. However, HRV and HEV were both thought to be possessed the capacity for viremia ( $\mathrm{Lu}$ et al. 2017). Another study reported that HRV (21\%) and HEV (9\%) were the second and third etiological cause of bronchiolitis in hospitalized infants after RSV in French (Jacques et al. 2006). A 2-year prospective study reported that RSV (27\%), HEV (25\%) and HRV (24\%) were the most important causative agents of acute expiratory wheezing in children in Finland (Jartti et al. 2004). These results were consistent with our study, which highlighted that more attention was needed for the important role of HEV and HRV in children with CAP.

HPIVs infection accounted for a significant proportion of lower respiratory tract infections in children (LjubinSternak et al. 2016). In another study that multiplex realtime PCR assay was used, HPIVs were identified in 9.07\% of the cases with severe acute respiratory infection in Beijing, China (Pan et al. 2017). In this study, HPIVs was the fourth most common causative agent, and four types of HPIVs were all detected. HPIV3 was the most predominant type, which was consistent with other studies (Thomazelli et al. 2017).

HBoV was identified in 2005 by Allander et al. (Allander et al. 2005). Several studies revealed the detection rate of $\mathrm{HBoV}$ ranged from 1.5\%-24.6\% (Schlaberg et al. 2017). In this study, $\mathrm{HBoV}(8.7 \%)$ was the fifth frequently detected viral pathogen, which was similar to other reports.

HMPV has been recognized as one of the most common causes of respiratory tract infection, with similar clinical manifestation to that of RSV (Papenburg and Boivin 2010). A cohort study conducted by U.S. group reported that HMPV was detected in 6\% (200/3490) of the hospitalized children (Edwards et al. 2013), which was similar to, but slightly lower than that of this study.

The seasonal pattern of respiratory virus varies in viruses. In this study, HEV/HRV infection was circulating all years round, and reached peak in spring and summer both in north and south China, which was consistent to other reports (Wang et al. 2010; Jain et al. 2015). The highest detection rates of HPIVs occurred in summer both in north and south China, which were similar to our previous study on children with acute respiratory tract infection from 2010 to 2012 in Beijing (Liu et al. 2013). The peak seasons of RSV, HMPV and Flu B were winter and spring both in north or south China in 2015, which was in agreement with most previous reports (Choi et al. 2006; Pilger et al. 2011; Xie et al. 2011; Xiao et al. 2012; Lu et al. 2013). Climate factors were recognized as the strongest predictors for influenza seasonality, including minimum temperature, hours of sunshine, and maximum rainfall (Azziz Baumgartner et al. 2012; Tamerius et al. 2013). Yu and his colleagues reported that Flu A presented distinct peak activity in northern provinces, southern provinces and provinces in intermediate latitudes in China ( $\mathrm{Yu}$ et al. 2013). Our findings supported the role of climatic factors in influenza transmission dynamics.

In recently years, the multiplex assays were increasingly applied to the diagnosis of infectious disease, with clinical significance, such as the improvement of diagnosis of coinfected cases, especially in severe pneumonia cases. In our study, multiple viral pathogens were detected in $19.1 \%$ of cases. Another study conducted among hospitalized children with CAP in U.S. showed similar results to, but higher than ours. This difference might be attributed to the difference in the populations studied, the year of analysis, and the screened pathogens (Liu et al. 2015).

In this study, viral pathogen presented in $60.0 \%$ of severe pneumonia patients. HEV/HRV, RSV, HBoV and HMPV accounted for more than $70 \%$ proportion of severe pneumonia cases infected with single virus. Our finding was consistent with the potentially severe outcome of RSV infections in children (Shi et al. 2015). However, HRV, $\mathrm{HBoV}$, and HMPV usually appeared in asymptomatic cases (Debiaggi et al. 2012; Principi and Esposito 2014; Jain et al. 2015; Ren et al. 2017). Several studies revealed that the prolonged viral shedding could cause viral nucleic acid of HRV, HBoV and HMPV presented in asymptomatic patients (Jartti et al. 2008; Martin et al. 2010; 
Dabaniyasti et al. 2020). Therefore, further studies are needed to confirm the correlation between these virus infections and the severity of pneumonia, and interpret these controversial consequences. In addition, viral pathogens were not detected in $40 \%$ of cases in our study, probably due to bacterial, mycoplasma or other unknown virus infection.

This study has several limitations. First, only hospitalized cases with CAP were enrolled. The spectrum of viruses in outpatient children might display different results. Therefore, our findings may not be representative of entire Chinese pediatric population. Further, although this study is a multicenter study, our results may not be representative of other regions in Chinese mainland, especially in Tibet, Xinjiang, Hainan and other remote provinces. Besides, in this study, we just screened the presence of viral pathogens in respiratory specimens from children with CAP. To better understand the profile of aetiology of CAP, further study is needed to investigate the role of other causal agents, including the bacterial and mycoplasma pneumoniae in children with CAP.

In conclusion, viral pathogens are frequently found in pediatric CAP cases, which may therefore play a vital role in the aetiology of CAP in Chinese mainland. RSV is the most common virus in hospitalized children with CAP. Flu A, HBoV, HAdV and $\mathrm{HCoVs}$ exert distinct seasonal patterns in north and south China. More confirmed evidence is needed to elucidate the causal association between infection of HRV, HEV, HMPV and HBoV and severe pneumonia cases.

Acknowledgements This study was supported by National Science and Technology Supported Projects (grant number: 2013BAI09B11), the National Major Science \& Technology Project for Control and Prevention of Major Infectious Diseases in China (grant number: 2018ZX10201002-008-008, 2017ZX10103004-004). We would like to thank all participating members of 13 hospitals for their assistance and collaboration in the samples and clinical data collection.

Author Contributions KS, ZX, BX, CL, ZC, LC, ZF, YS, AC, LD, and $\mathrm{YB}$ conceived and designed the experiments. BX, CL, ZC, LC, ZF, YS, AC, LD, YB, YS, LN, SY, FG, JY coordinated sample acquisition and recruited the CAP patients. YZ and CL performed the experiments and analyzed the data. YZ, CL and AS wrote and/or edited the manuscript. KS, ZX and YZ revised the manuscript. All authors meet the authorship criteria and approved publication of the manuscript.

\section{Compliance with Ethical Standards}

Conflict of interest The authors declare that they have no conflict of interest.

Animal and Human Rights Statement The study protocol was approved by the Ethical Review Committee of Capital medical university, Beijing Children's Hospital (2014-99). Individual written informed consent was obtained from the parents and/or guardians of all participants.

\section{References}

Allander T, Tammi MT, Eriksson M, Bjerkner A, Tiveljung-Lindell A, Andersson B (2005) Cloning of a human parvovirus by molecular screening of respiratory tract samples. Proc Natl Acad Sci U S A 102:12891-12896

Azziz Baumgartner E, Dao CN, Nasreen S, Bhuiyan MU, Mah EMS, Al Mamun A, Sharker MA, Zaman RU, Cheng PY, Klimov AI, Widdowson MA, Uyeki TM, Luby SP, Mounts A, Bresee J (2012) Seasonality, timing, and climate drivers of influenza activity worldwide. J Infect Dis 206:838-846

Berkley JA, Munywoki P, Ngama M, Kazungu S, Abwao J, Bett A, Lassauniere R, Kresfelder T, Cane PA, Venter M, Scott JA, Nokes DJ (2010) Viral etiology of severe pneumonia among Kenyan infants and children. JAMA 303:2051-2057

Caglayan Serin D, Pullukcu H, Cicek C, Sipahi OR, Tasbakan S, Atalay S, Pneumonia Study Group (2014) Bacterial and viral etiology in hospitalized community acquired pneumonia with molecular methods and clinical evaluation. J Infect Dev Ctries 8:510-518

Cantais A, Mory O, Pillet S, Verhoeven PO, Bonneau J, Patural H, Pozzetto B (2014) Epidemiology and microbiological investigations of community-acquired pneumonia in children admitted at the emergency department of a university hospital. J Clin Virol 60:402-407

Chen K, Jia R, Li L, Yang C, Shi Y (2015) The aetiology of community associated pneumonia in children in Nanjing, China and aetiological patterns associated with age and season. BMC Public Health 15:1422

Chen H, Weng H, Lin M, He P, Li Y, Xie Q, Ke C, Jiao X (2017) The clinical significance of filmarray respiratory panel in diagnosing community-acquired pneumonia. Biomed Res Int 2017:7320859

Choi EH, Lee HJ, Kim SJ, Eun BW, Kim NH, Lee JA, Lee JH, Song EK, Kim SH, Park JY, Sung JY (2006) The association of newly identified respiratory viruses with lower respiratory tract infections in Korean children, 2000-2005. Clin Infect Dis 43:585-592

Choudhary ML, Anand SP, Tikhe SA, Walimbe AM, Potdar VA, Chadha MS, Mishra AC (2016) Comparison of the conventional multiplex RT-PCR, real time RT-PCR and Luminex $x T A G(R) R V P$ fast assay for the detection of respiratory viruses. J Med Virol 88:51-57

Dabaniyasti D, Eksi F, Keskin O, Ozkars MY, Karsligil T, Balci I (2020) An investigation into respiratory tract viruses in children with acute lower respiratory tract infection or wheezing. Minerva Pediatr 72:45-54

DeAntonio R, Yarzabal JP, Cruz JP, Schmidt JE, Kleijnen J (2016) Epidemiology of community-acquired pneumonia and implications for vaccination of children living in developing and newly industrialized countries: a systematic literature review. Hum Vaccin Immunother 12:2422-2440

Debiaggi M, Canducci F, Ceresola ER, Clementi M (2012) The role of infections and coinfections with newly identified and emerging respiratory viruses in children. Virol J 9:247

Edwards KM, Zhu Y, Griffin MR, Weinberg GA, Hall CB, Szilagyi PG, Staat MA, Iwane M, Prill MM, Williams JV, New Vaccine Surveillance N (2013) Burden of human metapneumovirus infection in young children. N Engl J Med 368:633-643

Garcia J, Espejo V, Nelson M, Sovero M, Villaran MV, Gomez J, Barrantes M, Sanchez F, Comach G, Arango AE, Aguayo N, de Rivera IL, Chicaiza W, Jimenez M, Aleman W, Rodriguez F, Gonzales MS, Kochel TJ, Halsey ES (2013) Human rhinoviruses 
and enteroviruses in influenza-like illness in Latin America. Virol J 10:305

Guan X, Silk BJ, Li W, Fleischauer AT, Xing X, Jiang X, Yu H, Olsen SJ, Cohen AL (2010) Pneumonia incidence and mortality in Mainland China: systematic review of Chinese and English literature, 1985-2008. PLoS One 5:e11721

Jacques J, Bouscambert-Duchamp M, Moret H, Carquin J, Brodard V, Lina B, Motte J, Andreoletti L (2006) Association of respiratory picornaviruses with acute bronchiolitis in French infants. J Clin Virol 35:463-466

Jain S, Finelli L, Team CES (2015) Community-acquired pneumonia among U.S. children. N Engl J Med 372:2167-2168

Jain S, Williams DJ, Arnold SR, Ampofo K, Bramley AM, Reed C, Stockmann C, Anderson EJ, Grijalva CG, Self WH, Zhu Y, Patel A, Hymas W, Chappell JD, Kaufman RA, Kan JH, Dansie D, Lenny N, Hillyard DR, Haynes LM, Levine M, Lindstrom S, Winchell JM, Katz JM, Erdman D, Schneider E, Hicks LA, Wunderink RG, Edwards KM, Pavia AT, McCullers JA, Finelli L, Team CES (2015) Community-acquired pneumonia requiring hospitalization among U.S. children. N Engl J Med 372:835-845

Jartti T, Lehtinen P, Vuorinen T, Osterback R, van den Hoogen B, Osterhaus AD, Ruuskanen O (2004) Respiratory picornaviruses and respiratory syncytial virus as causative agents of acute expiratory wheezing in children. Emerg Infect Dis 10:1095-1101

Jartti T, Lee WM, Pappas T, Evans M, Lemanske RF Jr, Gern JE (2008) Serial viral infections in infants with recurrent respiratory illnesses. Eur Respir J 32:314-320

Liu CY, Xiao Y, Xie ZD, Ren LL, Hu YH, Yao Y, Yang Y, Qian SY, Zhao CS, Shen KL (2013) Viral etiology of acute respiratory tract infection among pediatric inpatients and outpatients from 2010 to 2012 in Beijing, China. Zhonghua Er Ke Za Zhi 51:255-259 (in Chinese)

Liu XJ, Zhang D, Wang S, Zhao YL, Teo M, Wang R, Cao Y, Ye X, Kang S, Zhao JZ (2015) Clinical features and long-term outcomes of moyamoya disease: a single-center experience with 528 cases in China. J Neurosurg 122:392-399

Ljubin-Sternak S, Marijan T, Ivkovic-Jurekovic I, Cepin-Bogovic J, Gagro A, Vranes J (2016) Etiology and Clinical characteristics of single and multiple respiratory virus infections diagnosed in croatian children in two respiratory seasons. J Pathog 2016:2168780

Lu G, Li J, Xie Z, Liu C, Guo L, Vernet G, Shen K, Wang J (2013) Human metapneumovirus associated with community-acquired pneumonia in children in Beijing, China. J Med Virol 85:138-143

Lu X, Schneider E, Jain S, Bramley AM, Hymas W, Stockmann C, Ampofo K, Arnold SR, Williams DJ, Self WH, Patel A, Chappell JD, Grijalva CG, Anderson EJ, Wunderink RG, McCullers JA, Edwards KM, Pavia AT, Erdman DD (2017) Rhinovirus viremia in patients hospitalized with communityacquired pneumonia. J Infect Dis 216:1104-1111

Martin ET, Fairchok MP, Kuypers J, Magaret A, Zerr DM, Wald A, Englund JA (2010) Frequent and prolonged shedding of bocavirus in young children attending daycare. $\mathrm{J}$ Infect Dis 201:1625-1632

Mathew JL, Singhi S, Ray P, Hagel E, Saghafian-Hedengren S, Bansal A, Ygberg S, Sodhi KS, Kumar BV, Nilsson A (2015) Etiology of community acquired pneumonia among children in India: prospective, cohort study. J Glob Health 5:050418

Nair H, Nokes DJ, Gessner BD, Dherani M, Madhi SA, Singleton RJ, O'Brien KL, Roca A, Wright PF, Bruce N, Chandran A, Theodoratou E, Sutanto A, Sedyaningsih ER, Ngama M, Munywoki PK, Kartasasmita C, Simoes EA, Rudan I, Weber MW, Campbell H (2010) Global burden of acute lower respiratory infections due to respiratory syncytial virus in young children: a systematic review and meta-analysis. Lancet 375:1545-1555

Ning G, Wang X, Wu D, Yin Z, Li Y, Wang H, Yang W (2017) The etiology of community-acquired pneumonia among children under 5 years of age in mainland China, 2001-2015: a systematic review. Hum Vaccin Immunother 13:2742-2750

Oumei H, Xuefeng W, Jianping L, Kunling S, Rong M, Zhenze C, Li D, Huimin Y, Lining W, Zhaolan L, Xinmin L, Hua X, Zhiyan J, Yanning L, Yan $\mathrm{H}$, Baoqing $\mathrm{Z}$, Xiaochun $\mathrm{F}$, Chunhui $\mathrm{H}$, Yonghong J, Xue Z, Wei W, Zi W (2018) Etiology of community-acquired pneumonia in 1500 hospitalized children. J Med Virol 90:421-428

Padilla Ygreda J, Lindo Perez F, Rojas Galarza R, Tantalean Da Fieno J, Suarez Moreno V, Cabezas Sanchez C, de Santa M, Gadea S, Hijar Guerra G (2010) Etiology of community acquired pneumonia in children 2-59 months old in two ecologically different communities from Peru. Arch Argent Pediatr 108:516-523

Pan Y, Zhang Y, Shi W, Peng X, Cui S, Zhang D, Lu G, Liu Y, Wu S, Yang P, Wang Q (2017) Human parainfluenza virus infection in severe acute respiratory infection cases in Beijing, 2014-2016: a molecular epidemiological study. Influenza Other Respir Viruses 11:564-568

Papenburg J, Boivin G (2010) The distinguishing features of human metapneumovirus and respiratory syncytial virus. Rev Med Virol 20:245-260

Pilger DA, Cantarelli VV, Amantea SL, Leistner-Segal S (2011) Detection of human bocavirus and human metapneumovirus by real-time PCR from patients with respiratory symptoms in Southern Brazil. Mem Inst Oswaldo Cruz 106:56-60

Principi N, Esposito S (2014) Paediatric human metapneumovirus infection: epidemiology, prevention and therapy. J Clin Virol 59:141-147

Ren L, Yang D, Ren X, Li M, Mu X, Wang Q, Cao J, Hu K, Yan C, Fan H, Li X, Chen Y, Wang R, An F, An S, Luo M, Wang Y, Xiao Y, Xiang Z, Xiao Y, Li L, Huang F, Jin Q, Gao Z, Wang J (2017) Genotyping of human rhinovirus in adult patients with acute respiratory infections identified predominant infections of genotype A21. Sci Rep 7:41601

Schlaberg R, Ampofo K, Tardif KD, Stockmann C, Simmon KE, Hymas W, Flygare S, Kennedy B, Blaschke A, Eilbeck K, Yandell M, McCullers JA, Williams DJ, Edwards K, Arnold SR, Bramley A, Jain S, Pavia AT (2017) Human bocavirus capsid messenger rna detection in children with pneumonia. J Infect Dis 216:688-696

Shi T, Balsells E, Wastnedge E, Singleton R, Rasmussen ZA, Zar HJ, Rath BA, Madhi SA, Campbell S, Vaccari LC, Bulkow LR, Thomas ED, Barnett W, Hoppe C, Campbell H, Nair H (2015) Risk factors for respiratory syncytial virus associated with acute lower respiratory infection in children under five years: systematic review and meta-analysis. J Glob Health 5:020416

Subspecialty Group of Respiratory Diseases, The Society of Pediatrics, Chinese Medical Association The Editorial Board, Chinese Journal of Pediatrics (2013) Guidelines for management of community acquired pneumonia in children (the revised edition of 2013) (II). Zhonghua Er Ke Za Zhi 51:856-862 (in Chinese)

Tamerius JD, Shaman J, Alonso WJ, Bloom-Feshbach K, Uejio CK, Comrie A, Viboud C (2013) Environmental predictors of seasonal influenza epidemics across temperate and tropical climates. PLoS Pathog 9:e1003194

Thomazelli LM, Oliveira DBL, Durigon GS, Whitaker B, Kamili S, Berezin EN, Durigon EL (2017) Human parainfluenza virus surveillance in pediatric patients with lower respiratory tract infections: a special view of parainfluenza type 4. J Pediatr (rio j) 94:554-558 
Wang W, Cavailler P, Ren P, Zhang J, Dong W, Yan H, Mardy S, Cailhol J, Buchy P, Sheng J, Fontanet A, Deubel V (2010) Molecular monitoring of causative viruses in child acute respiratory infection in endemo-epidemic situations in Shanghai. J Clin Virol 49:211-218

Wang L, Zhao M, Shi Z, Feng Z, Guo W, Yang S, Liu L, Li G (2016) A GeXP-Based Assay for Simultaneous Detection of Multiple Viruses in Hospitalized Children with Community Acquired Pneumonia. PLoS One 11:e0162411

Xiao NG, Zhang B, Duan ZJ, Xie ZP, Zhou QH, Zhong LL, Gao HC, Ding XF, Zeng SZ, Huang H, Hou YD (2012) Viral etiology of 1165 hospitalized children with acute lower respiratory tract infection. Zhongguo Dang Dai Er Ke Za Zhi 14:28-32 (in Chinese)

Xie ZD, Xiao Y, Liu CY, Hu YH, Yao Y, Yang Y, Qian SY, Geng R, Wang JW, Shen KL (2011) Three years surveillance of viral etiology of acute lower respiratory tract infection in children from 2007 to 2010. Zhonghua Er Ke Za Zhi 49:745-749 (in Chinese)

Xu L, Zhu Y, Ren L, Xu B, Liu C, Xie Z, Shen K (2017) Characterization of the nasopharyngeal viral microbiome from children with community-acquired pneumonia but negative for Luminex xTAG respiratory viral panel assay detection. J Med Virol 89:2098-2107

Yu H, Alonso WJ, Feng L, Tan Y, Shu Y, Yang W, Viboud C (2013) Characterization of regional influenza seasonality patterns in China and implications for vaccination strategies: spatio-temporal modeling of surveillance data. PLoS Med 10:e1001552

Zhang Q, Guo Z, Bai Z, MacDonald NE (2013) A 4 year prospective study to determine risk factors for severe community acquired pneumonia in children in southern China. Pediatr Pulmonol 48:390-397 